\title{
Contribuições para a sexualidade infantil ${ }^{* 1,2}$
}

A assexualidade da criança é um preconceito e, como todo preconceito, quanto mais antigo e infundado ele é, mais profundamente enraizado na consciência cultural da humanidade está. Assim como o conto de fadas da "inocência paradisíaca" do homem primitivo (Urmenschen) tomou o lugar adequado como conhecimento histórico-cultural da evolução da sociedade humana, também é preciso substituir urgentemente a suposição ingênua da inocência sexual do indivíduo imaturo por uma nova, verdadeira, baseada nas evidências da pesquisa psicanalítica. Nem a psicologia, que está longe do pulsar da vida e produz especulações abstratas, quanto a psicologia experimental, com suas experiências laboratoriais, conhecem as sensações sexuais da criança, imperando a ignorância hipócrita moralista daqueles que, inflamados, não conseguem conversar sobre tal conhecimento polêmico. Mas aqueles que conseguem "mergulhar na vida

*1 Esta tradução faz parte da pesquisa de pós-doutorado Escritas da clínica psicanalítica com crianças: história e transmissão da experiência, de Adela Judith Stoppel de Gueller, realizada sob a supervisão da Profa. Dra. Ana Costa, no Programa de Pós-graduação em Psicanálise da Universidade do Estado do Rio de Janeiro - UERJ, e tem financiamento da Capes.

*2 Tradução de Angela May; Revisão técnica de Adela Judith Stoppel de Gueller.

*3 Não inseri no texto as fontes exatas, mas gostaria de mencionar os trabalhos de Freud e de seus alunos, principalmente "Três ensaios sobre a teoria da sexualidade". [N.A.] 


\section{CLÁSSICO DA PSICANÁLISE}

humana" sem preconceitos poderão observar a sexualidade infantil passo a passo, com clareza e sem ambiguidades.

A criança não experimenta a vida sexual da mesma forma que o adulto, que alcança seu ápice e seu objetivo no ato sexual. A pulsão sexual do adulto (Sexualtrieb) é complexa, uma vez que é composta por diversos elementos pulsionais e passa por grandes transformações até chegar à puberdade. Conseguimos identificar os componentes dessa pulsão nos primeiros meses de vida do bebê. Suas fontes estão relacionadas às necessidades vitais como a alimentação e a excreção. Tudo isso está ligado aos sentimentos de prazer e desprazer. Com o desenvolvimento, excitam-se as zonas erógenas do próprio corpo: boca, anus, genitais etc. Há um ganho prazeroso com a alimentação e a excreção, abstraem-se essas primeiras fontes e se transferem aos objetos do ambiente, que, em contato com as zonas erógenas, tornam-se fontes de prazer. O autoerotismo evolui para o amor objetal, cujas primeiras expressões já são perceptíveis no bebê - estão relacionadas com o ato de sugar na amamentação e são dirigidas à pessoa que cuida e amamenta.

Um belo exemplo me é contado pela mulher de um colega. Ela queria dar leite de vaca, na mamadeira, a seu bebê de seis meses, que até então só havia mamado no peito. Ele berrava, ficava inquieto, só se acalmava no peito da mãe. Até que a mulher teve a ideia de pegá-lo no colo, em vez de apenas dar a mamadeira, e o bebê sugou normalmente até adormecer. $\mathrm{O}$ episódio se repetiu muitas vezes. Esse caso não é uma exceção, mas a regra, e é conhecido por mães experientes. Faz crer que não é o gosto estranho ou desagradável que leva à insatisfação, mas a falta do aconchego da mãe; o importante é o bebê tocar o seio materno macio e quente com sua mãozinha. Ele não quer abdicar dos ganhos secundários que obteve com o ato de mamar, já que esses ganhos se tornaram fonte de prazer. Para ele, essas sensações, obtidas pelos ganhos secundários, são impulsos talvez tão fortes quanto o ato de se alimentar ou o desprazer na fome. Também é sabido como o bebê brinca com o seio sem sugar, quando não tem mais fome, e grita quando o retiram. Eu ainda gostaria de acrescentar que o bebê de seis meses conhecia muito bem a voz da mãe, que era sua voz predileta.

Com esse exemplo simples e corriqueiro, podem-se verificar as primeiras expressões do amor objetal. A pequena criança transferiu para sua mãe o prazer evocado com o sugar e os cuidados maternos. $\mathrm{O}$ toque íntimo corporal materno nas zonas erógenas (nessa idade, principalmente boca e mãos) virou fonte de prazer. 
O próximo exemplo deve nos levar um passo adiante. Por circunstâncias externas, uma jovem senhora foi obrigada a amamentar no peito sua única menina, por um ano e dez meses. A pequena acostumou-se a puxar e beliscar levemente o seio, e até hoje é para ela o maior deleite. Para convencer a mãe a levá-la ao colo e deixá-la puxar-lhe o seio, ela não hesita em usar todos os meios de que dispõe: grita e chora horas a fio, não quer comer, fica mal-humorada e desobediente. Ela se acalma imediatamente, ficando boazinha e obediente, quando alcança o que deseja. Há alguns meses, ela adoeceu com uma angina e febre alta, e a mãe cuidou dela com zelo e ternura. A criança berrava quase ininterruptamente e, para acalmá-la, a mãe a deixava puxar e beliscar seu seio de leve. A angina durou apenas alguns dias, mas desde então a pequena tem uma nova arma para conseguir o prazer desejado: simula uma doença. Chora, se queixa de dor de cabeça, de dor no corpo, de dor nas pernas, na garganta; e o sofrimento desaparece no instante em que ela é posta no colo da mãe, preocupada e rendida, tendo o prazer com o qual está habituada. Uma típica fuga neurótica para a doença, uma histeria em status nascendi. $\mathrm{O}$ caso parece quase um experimento.

A relação entre pulsão sexual (Sexualtrieb) e pulsão de alimentação 514 (Esstrieb) foi muitas vezes elucidada por Freud e seus alunos. Na infância, como se sabe, é grande o vício de comer guloseimas, e ainda não está desenvolvida a prevalência dos genitais como fonte de prazer. Nos jovens de ambos os sexos - , com o início da vida sexual, o vício das guloseimas dá lugar à ingestão de álcool e/ou nicotina. Em mulheres jovens que não conhecem a satisfação da pulsão sexual, o vício pode se intensificar e consolidar. Em adultos cuja libido fica insatisfeita, pode também se desenvolver, como substituto, um verdadeiro vício por guloseimas, sobretudo em mulheres ou em pessoas idosas após o climatério. Na literatura psicanalítica, é amplamente discutido o parentesco da expressão de ambas as pulsões, no sonho, na neurose e na psicose. Aqui, cito apenas dois exemplos bem concisos. Uma mulher histérica, cujo marido sofria de ejaculação precoce, acorda após o coito fracassado fissurada de fome. Um de meus pacientes tinha essa sensação todas as noites. Ele dormia no quarto com seu irmão mais velho, que era o objeto de seus desejos homossexuais inconscientes. Prescrevi que o irmão mais velho se mudasse para outro quarto: o paciente passou a dormir tranquilamente, e a fissura por comida não apareceu.

A estimulação (Reizung) no ânus e no exterior do aparelho urinário causada pela excreção de secreções e excrementos como urina e fezes forma essas partes do corpo como zonas erógenas privilegiadas. Por esse caminho, 


\section{CLÁSSICO DA PSICANÁLISE}

chega-se ao desenvolvimento do erotismo anal e da pulsão masturbatória (Masturbationstriebes). A masturbação infantil é suficientemente conhecida, portanto, não precisa ser mais aprofundada. Ela é um processo psicológico normal, a que talvez se possa atribuir um significado biológico - o desenvolvimento da parte externa do aparelho urogenital torna-se um órgão sexual especial. No bebê, me parece, a pulsão para a masturbação é bastante forte; com o tempo, se atenua e volta a se fortalecer num momento muito importante, entre os 3 e os 4 anos. Essa é talvez uma época crítica no desenvolvimento de um indivíduo, quando há uma primeira grande evolução psíquica: a primeira adaptação às exigências culturais da educação e do ambiente e as primeiras repressões (Unterdrückungen) das moções de desejos (Wunschregungen), sobre as que recai a amnésia infantil e que formam o conteúdo do inconsciente. Do bom andamento e da resolução dessa evolução dependem a saúde anímica e a força do indivíduo para aumentar ou diminuir a forte disposição para a neurose e a psicose. Após esse período, surgem os primeiros sintomas neuróticos comuns como pavor noturno, enurese noturna, fobias, gagueira etc. O conflito psíquico se desenvolve em consequência do amor objetal (incestuoso), mais ou menos consciente, que leva ao aumento da moção libidinosa da masturbação. Esse período masturbatório recai sob amnésia.

Um bom exemplo do exposto é o filho de 4 anos de um colega. ${ }^{1}$ Acometido de uma doença infecciosa, foi cuidado pela mãe de forma muito zelosa e delicada e logo melhorou. No entanto, precisou ficar acamado mais algumas semanas. As outras crianças estavam afastadas da casa. Ele era o único objeto materno. A mãe transbordava amor e alegria, o que despertou no menino uma paixão ciumenta pela mãe, que até então sentia como mais distante. Ele a abraçava e beijava, não permitia que ela se afastasse de sua cama de dia ou à noite.

- Você deve dormir comigo agora, não com o papai, no quarto! gritava ele, chorando.

Nessa situação, masturbava-se continuamente, queixava-se de vontade de fazer xixi e pedia a todo momento o urinol, mas na maioria das vezes não saía nada. O exame de urina estava normal, assim como o exame clínico. Quando a mãe foi substituída pela tutora nos cuidados com o garoto, ele se acalmou e desapareceu a urgência urinária. Assim, essa urgência era apenas

${ }^{1}$ Freud relata de forma precisa esses acontecimentos no Anuário para pesquisa psicológica e psicanalitica (Jahrbuch fuer psychoanalytische und psychologische Forschung), onde publicou "Analise de uma fobia de um menino de 5 anos". (N.A.) 
um pretexto para se exibir perante a mãe. Nesse mesmo período, o menino manifestava repúdio, irritação e ódio pelo pai. Seu comportamento tinha claramente um caráter de rivalidade e ciúme da mãe.

Há uma nova intensificação da pulsão masturbatória na segunda grande evolução do desenvolvimento, que se dá na puberdade e cuja intensidade pode variar em cada indivíduo.

Nenhuma dessas observações é fora do comum ou surpreende, e podemos comprovar passo a passo a exatidão de nossas conclusões. Análises detalhadas confirmam os achados. Quero acrescentar aqui: especialmente análises com crianças de 8 a 10 anos.

Um garoto forte e saudável sofre de "ataques": de repente ele grita, anda alguns passos, mexe as mãos como para se defender, arregala e vira os olhos para cima, olha para o infinito e pequenos espasmos movem a musculatura da boca. Depois, ele cai devagar e fica deitado calmamente; não reage a picadas na pele, e a reação das pupilas é pouco clara. Uma vez eu imitei um ataque com uma picada no nariz. Deixado sozinho, após alguns minutos, ele de repente acorda e quase não se lembra do ataque. Uma vez também observei um ataque severo desse garoto: parecia um típico ataque epilético, mas começava como o descrito, durava 20 minutos e recaía num coma pós-epilético por horas. Os ataques severos aconteciam a cada duas semanas, duas vezes seguidas.

$\mathrm{O}$ primeiro ataque foi há cinco anos. Na época, a mãe o levou a um sanatório. Ele foi eletrizado algumas vezes, e os ataques desapareceram completamente. Após uma pausa de cinco anos, os ataques voltaram com uma frequência de 10 a 12 vezes ao dia. Intelectualmente, o garoto ficou atrasado, mas era relativamente esperto. Tinha uma pronunciada pulsão por caminhar (Wandertrieb), era irritável, mentiroso, teimoso mas de bom coração, sugestionável e bastante influenciável. Também apresentava degenerações físicas: tinha um corpo muito forte e gordo, cabeça e testa pequenas, orelhas deformadas e o céu da boca alto.

Era visível sua afeição apaixonada pela mãe. $\mathrm{Na}$ análise, isso foi logo expressado. Na primeira sessão, ele me contou sobre o grande amor e a saudade que tinha da mãe. Ele também gostaria muito de ter outra vez um penico "muito lindo" que sua mãe lhe havia comprado outrora.

$\mathrm{Na}$ segunda sessão, se queixou de seus medos: tinha medo no quarto escuro, medo de bandidos e de contos de fadas horríveis, de que no entanto gostava muito. Em sessão, com algum receio, faz alguns desenhos de contos de fadas, bastante insignificantes. 


\section{CLÁSSICO DA PSICANÁLISE}

Na sessão seguinte, começou com os mesmos contos e músicas, repetiu-os com muita calma e sem medo (Angstgefühl), o que ele mesmo percebeu; então, falou de seu grande medo (Angst) do diabo. ${ }^{2}$ Ele já o vira; era noite, e foi quando começaram os ataques.

Ele dormia no mesmo quarto que o irmão, mas queria ir para a cama da mãe. A mãe não permitiu, uma vez que o pai não gostava quando ele dormia com ela, mas ele chorou tanto que ela acabou consentindo. Deitado na cama dela, espreitava pela porta entreaberta o quarto escuro das crianças. Nesse momento, percebeu o diabo. Ao se lembrar disso, gritou e pulou assustado, com grande excitação, do sofá.

$\mathrm{Na}$ quarta sessão, retomou o episódio ocorrido na sessão anterior. Lembrou-se de que, naquela noite, estava sozinho na cama da mãe, sem ela. A mãe estava no quarto, e o pai não estava em casa. Então ele vê o diabo, se assusta, quer pular da cama, grita alto e faz movimentos de defesa, exatamente como no ataque. Com o passar do tempo, vai se acalmando: a visão do diabo se modifica, se transforma no pai, que tem o mesmo terno, a mesma barba, e assim por diante. O paciente reconhece na visão horrível do diabo exatamente a figura do pai, gargalha e explica que não tem mais medo do diabo.

$\mathrm{Na}$ quinta sessão, conta o seguinte: ele sempre tem muito medo do pai e do irmão. O irmão mais velho certa vez lhe disse:

- Você deve ter sempre medo do pai. Quando o pai fica muito bravo, ele nem bate, ele te joga para o teto e depois você cai morto no chão.

Depois ele vê uma cena: numa briga entre o pai e a mãe, o pai quer esquartejá-la com uma faca. O pai se transforma num vilão e esbofeteia a mãe à noite. Também chama seu irmão mais velho, que era ruivo, de vilão ou vilão vermelho. Ele o xinga muito e quer matá-lo a pauladas.

- Porque ele quer abraçar e beijar a mãe.

- Ele não deve fazer isso, eu não suporto isso, eu mato ele a pauladas - gritava raivosamente, debatendo-se com as mãos e os pés.

Seguem-se fantasias de lutas sangrentas com os irmãos, em que ele se consagra vencedor e mata-os a pauladas.

- Porque eles ousaram beijar a minha mãe.

${ }^{2}$ Optamos por traduzir Angst por "medo", que é seu sentido literal em alemão. Embora "ansiedade" ou "angústia" sejam traduções frequentes, o dicionário comentado fala em ameaças tanto específicas (Angst vor $=$ "medo de") como inespecíficas (Angst = "medo") (Hans, L. Dicionário Comentado do Alemão de Freud. Rio de Janeiro: Imago, 1996. Verbete: Angústia, Ansiedade, Medo, Angst.) (N. da T.) 
Depois ele conta que odeia os irmãos há "muitos anos", por ciúmes dela.

- Quando o irmão vermelho quer me provocar, ele diz:

— Eu vou beijar a mãe. - Aí, eu fico com raiva e bato nele.

$\mathrm{Na}$ sessão seguinte, repete primeiro as fantasias da luta com o irmão vermelho, com a seguinte modificação: o paciente, junto com seus amigos, mata os amigos do irmão a pauladas, mas o irmão salva a própria vida fugindo.

Depois, o paciente vê sua mãe doente na cama. Ele cuida dela, dá-lhe leite, água, remédios...

— Também o "vermelho" está presente. Ele está totalmente nu e quer uma camisa limpa; a mãe lhe dá uma camisa.

Depois vê o pai, que quer bater nele, uma vez que tinha beijado a mãe.

- O pai não deixa que eu durma com ela, ele fica com raiva.

Depois ele vê o pátio da igreja de sua casa onde seu irmão está sepultado. Ele está de pé, ao lado da cova recém-aberta do irmão, ao lado do pai, durante um longo tempo, em silêncio. Não consegue se mexer e fica com tanto medo... Aí, se faz um grande silêncio, enquanto o paciente vai ficando inquieto e com mais medo. Com grande resistência, tremendo de medo (Angst), ele conta:

- Eu vi no sonho, durante a noite, que o meu pai me pegou, me jogou no teto, eu caí no chão e estava morto.

Ele treme inteiro, grita, chora e defende-se com toda a força - como em seus ataques. Depois se acalma, mas olha muito tempo medrosamente (ängstlich) à sua volta e para o teto, onde acredita ver uma fresta. Depois fica sentado, sonolento, triste, pensativo, suspirando por muito tempo. Segundo seu relato, o paciente teve esse sonho um pouco antes da morte de seu irmão.

Na sexta sessão, contou que um dia o pai queria arremessá-lo ao teto e que fez o mesmo também com a mãe — pegou-a pela cintura e a jogou para cima. Após longa resistência, o paciente contou que viu o coito dos pais. Ao contá-lo, ficou muito agitado e angustiado (ängstlich). Isso tinha ocorrido havia muitos anos; na época, ele era bem pequeno. Depois apareceu uma fantasia de concepção, ou provavelmente uma fantasia de nascimento:

- Eu era na época muito pequeno, tão pequeno que eu estava debaixo da cama da minha mãe e vi tudo através de um pequeno buraco na cama dela. Vi como eles faziam.

- Eu corri e chamei meus irmãos, todos nós estávamos lá, em pé, olhando pelo buraco e víamos tudo... etc.

Nesse ponto, infelizmente, a análise foi interrompida, mas, com o material existente, pode-se ter uma ideia da vida psíquica do garoto. Por excesso 


\section{CLÁSSICO DA PSICANÁLISE}

de carinho da mãe, sua libido despertou muito forte e precocemente e se fixou nela. Daí surgiu uma rivalidade com o pai e, consequentemente, um grande medo (Angst) e ódio dele. Também se identifica com a mãe em contraposição ao pai porque, na sua fantasia, o pai os trata — a ele e à mãe — da mesma maneira: ele também a joga no teto. A morte do irmão e seu enterro são episódios patogênicos que intensificam esses conflitos psíquicos até torná-los indissolúveis. O terror por tudo o que foi vivido antes do aparecimento enigmático da morte ficou associado agora à violência paterna (pai $=$ diabo), o medo frente ao pai vira terror, preparando terreno fértil para a fala descuidada do irmão. O medo neurótico tem uma conotação prazerosa. Ele também gosta muito dos contos de fadas aterrorizadores e de suas canções, uma vez que neles a morte aparece como castigo pelo carinho materno. Esses dois sentimentos intensos - o amor e o terror — têm uma raiz comum: se aproximam e afastam num conflito indissolúvel, que só se modifica quando encontra uma saída. A realidade efetiva ${ }^{3}$ (Wirklichkeit) proíbe o amor com a mãe, mas o sonho e a fantasia o admitem. Por trás da terrível máscara da morte, está velada a realização de desejos recalcados, uma vez que a morte é sempre o castigo merecido pela realização do amor.

Os ataques têm provavelmente uma dupla natureza: histérica e epilética. A primeira é expressão corpórea de uma luta modificada de seus sentimentos. São movimentos defensivos inconscientes contra o pai e, ao mesmo tempo, se assemelham aos de um coito, resultado da identificação com a mãe. Gostaria de deixar em aberto se o mecanismo psíquico tem algo a ver com a epilepsia. ${ }^{4}$

Uma menina de oito anos sofre de ataque há cerca de um ano e meio quando brinca, lê ou anda. De repente, ela para; seu olhar fica "parado e sem expressão", fixado num ponto, os olhos arregalados virados para cima e um pouco trêmulos; em volta da boca, há pequenos espasmos. Logo após esse ataque, aparece uma urgência urinária. $\mathrm{O}$ ataque dura 2-3 segundos. A sensibilidade não sofre alterações durante o ataque, assim como não há alteração de consciência, de modo que a menina conseguia descer uma escada bem alta ou descer de um aparelho numa aula de ginástica.

${ }^{3}$ A partir de Freud, Wirklichkeit designa a realidade efetiva, que se contrapõe à realidade psíquica. (N. da T.)

${ }^{4} \mathrm{O}$ trabalho de W. Stekel "Die psychische Behandlung der Epilepsie" (“O tratamento psíquico da epilepsia") (caderno 5/6 desta revista) ainda não estava publicado quando eu escrevi este trabalho. Acredito que este caso seja uma pseudoepilepsia no sentido de Stekel. (N.A.) 
A paciente nasceu prematura de sete meses, pequena e fraca. Aos seis meses, falava "papai" e "mamãe" e depois parou de falar. Só aos 3 anos, após ser curada de uma doença crônica de ouvido, ela realmente começou a falar.

Segundo a mãe, a paciente é muito irritável, intratável e sonhadora. Tem uma fantasia fértil e uma tendência a mentir. É "terrivelmente carinhosa", receptiva a toda influência e mostra uma grande necessidade de afeto, assim como tem uma grande capacidade de amar.

Logo no primeiro dia, a pequena contou:

- Quando eu quero dormir, vejo tudo o que vi e ouvi no dia. Quando acordo, não vejo, mas é só colocar as mãos na frente dos olhos que eu vejo um ladrão bem mau. Ele vai me devorar logo. Um bando de ladrões. Eles têm unhas pontudas, eles arranham e mordem, eles têm um rabo e chifres, são vermelhos, iguais ao diabo. Depois, vejo um caçador com sua espingarda, muitos pássaros e corvos. Eles roubam ouro e prata, mesas, camas, pequenas bonecas, anões, coelhos, o Papai Noel e brinquedos. Depois uma Maria ${ }^{5}$ e a Dama Mefisto... Nesse momento, sinto medo (Angst). Eles cortam minha barriga e eu não sinto nada. Depois, eles tiram meu estômago e o comem. Depois, com um alicate, tiram meus dentes, meus ouvidos e meus olhos e me batem. Depois, vem o caçador e os mata e o cão de caça morde eles. Depois, vem a cegonha e traz um pequeno bebê para a mãe, mordendo ela e o bebê na perna.

Quero acrescentar que o pai da menina era cantor de ópera e na época estudava o Fausto, de Gounod.

É fácil identificar as pessoas corretas e o verdadeiro sentido por trás do teto transparente das fantasias infantis comuns, de brinquedos e personagens de contos de fadas. Os bandidos com suas espingardas se transformam em diabo; o diabo é, no entanto, o pai, que estuda a ópera que trata do diabo. A Dama Mefisto é a mãe, e tudo é uma fantasia de concepção e nascimento, como explicita o final. Chama atenção a cena sadomasoquista em que se corta a barriga e se corta e devora o estômago através da Dama Mefisto. É uma analogia construída a partir da observação da mãe preparando, cortando e cozinhando um frango. Aqui se expressam as ideias de que o bebê entra na barriga da mãe como a carne quando é comida - pela boca - e, sobre o nascimento, de que o bebê é retirado cortando-se a barriga da mãe.

Um difuso saber sobre o papel do pai também transparece, uma vez que o cão de caça do caçador morde a mãe, assim como a cegonha. $O$ cachorro do pai é identificado com a cegonha do pai, que traz o bebê. (Ele também

${ }^{5}$ Refere-se a Maria do conto “João e Maria”, dos irmãos Grimm. (N. da T.) 


\section{CLÁSSICO DA PSICANÁLISE}

cantou o Freischütz. ${ }^{6}$ É interessante a comparação com o caso anterior. Com o garoto, o pai é apenas o malvado diabo, que rouba a mãe e traz a morte; no caso da menina, ele é um protetor bom, e o medo e as fantasias sadomasoquistas está relacionado à Dama Mefisto.

Na sessão seguinte, a paciente conta um sonho:

- Mamãe estava na escola e fez "olhos grandes", depois eu chorei. Eu entrei e vi um menino e uma menina; eles brincavam de esconde-esconde e depois vieram as outras coisas.

Ela se identifica com a mãe. A mãe vai à escola e faz "olhos grandes", e a menina (a própria paciente) brinca de esconde-esconde com os meninos e "outras coisas". Por "outras coisas", ela entende "tudo que a mãe faz: arrumar os quartos, fazer compras e principalmente cuidar das crianças". Para "olhos grandes", a paciente dá a seguinte explicação: "Knecht Ruprecht, ${ }^{7}$ o Papai Noel faz 'olhos grandes', e também o querido Deus, quando as crianças são desobedientes”.

- Quando as crianças fazem algo feio, aí eles fazem olhos grandes. Eu vi como o Max fez com os olhos, aí eu também comecei a fazer "olhos grandes", por isso que acontece sempre. Quando fazemos algo e dizemos "não", daí se fazem "olhos grandes."

Logo, "fazer olhos grandes" significa fazer algo proibido e ter consciência pesada. Também não era difícil descobrir o que a paciente entendia por "feio", "coisas ruins", "proibido". Já na primeira sessão, ela se queixou de coceira no corpo todo, assim como no ânus e na vagina, e explicou que só não se coçava nessas regiões porque era feio. A mãe acrescentou:

- A paciente e seus irmãos — um menino de 6 e uma menina de 4 são muito apaixonados e "cínicos" — têm um grande interesse por genitais e flatulências. Quando brincam com as mãos, pegam nos genitais uns dos outros. Há algum tempo, a paciente tem evitado fazer isso e xinga os irmãos mais novos quando eles o fazem.

${ }^{6} \mathrm{~A}$ ópera é de Carl Maria von Weber, O franco-atirador. (N. da T.)

${ }^{7}$ Esse conto não veio para o Brasil, mas a tradução é Servo Ruprecht, ajudante de São Nicolau, o velhinho que faz brinquedos para as crianças no Natal e que nós chamamos de Papai Noel. O Servo Ruprecht é um velho manco de barbas longas que anda apoiado numa vara. Ele é enviado à terra por São Nicolau, ou, dependendo da versão do conto, por Christikind (uma figura alada e angelical), que lá do céu observa com "olhos grandes" o comportamento das crianças. Ruprecht interroga as crianças sobre seu comportamento durante o ano: se não foram boazinhas, ele pode bater nelas com sua vara. Na Alemanha, Ruprecht era um nome comum para o Diabo. Considerando o teor do conto, talvez se possa fazer uma analogia entre o Servo Ruprecht e o nosso "homem do saco", que leva embora as crianças que "se comportam mal". (N. da T.) 
Numa das visitas seguintes, fico sabendo - depois de uma grande resistência por parte da pequena - que, entre ela e a irmã menor, com quem dorme no mesmo quarto, existe há alguns meses um verdadeiro caso de amor, no qual a paciente representa a mulher e, a irmãzinha, o homem. Toda noite, a menor manipula a genitália da maior com o pé e tenta enfiar o dedão na vagina da paciente. Mas, antes disso, um ano e meio atrás, um menino chamado Max tentou várias vezes ter intercurso sexual com a paciente. Isso também foi confirmado pela mãe. A paciente é colocada para dormir sozinha, e tomam-se medidas de precaução contra a masturbação. Após dois dias, a mãe relata:

- Antes, pela manhã, a paciente sempre era briguenta, amuada, irritada, apática. Nos últimos dois dias, no entanto, está alegre e refrescada e, pela manhã, só tem de dois ou três ataques, quando antes tinha ataques a cada cinco minutos. Hoje, ela estava sentada na cama, as pernas apertadas uma na outra e, entre as pernas, ela tinha um pau. Ela mexia o pau num vaivém, seu corpo estremecia numa espécie de espasmos e de repente ela teve um ataque. Ontem, ela ouviu o pai contar uma cena de amor do Fausto. Ficou visivelmente excitada e teve um ataque... Eu a proibi de abraçar e beijar os irmãos com paixão, e ela disse:

— Então, você não deve... o papai. — E se conteve.

Logo depois, a paciente foi levada a um abrigo de crianças por alguns meses. Os relatos da educadora durante sua estadia eram bastante razoáveis. Só havia, no máximo, três ataques ao dia e, nos últimos tempos, não havia mais ataques; a pequena ficou mais calma, mais obediente e mais amável. Lá não se verificou a masturbação. A paciente voltou para casa e logo se instalou a situação anterior; os ataques voltaram a aparecer, primeiro de forma esporádica, depois com mais frequência, não tanta como antes do tratamento. As antigas irritações e os humores reapareceram, e ela voltou ao velho vício da masturbação. Ela também demonstrava uma grande paixão pelo pai e um repúdio pela mãe.

A afirmação da paciente de que ela vira os ataques em Max foi parcialmente confirmada. A mãe contou de um amiguinho que se chamava Fritz e que tinha ataques similares. $O$ garoto também veio para os meus cuidados.

Fritz $^{8}(\ldots), 9$ anos, sofre de ataques há cinco anos. Antes disso, sofreu durante algum tempo de terror noturno. Ele é bastante irritável, tem uma

${ }^{8}$ Esse caso é citado por Freud em "Totem e tabu" para ilustrar a semelhança com o caso Hans: "Em todos os casos, era o mesmo: quando se questionavam os meninos, a angústia se referia, no fundo, ao pai e só se havia deslocada ao animal" (Freud, S. Tótem y tabú. [1913] Buenos Aires: Amorrortu, 1996, p. 130.) (N. da T.) 


\section{CLÁSSICO DA PSICANÁLISE}

fantasia fértil e uma tendência a mentir. De resto, física e psiquicamente é normal, aprende bem, é superpontual, obediente, ordeiro e zela por estar limpo. ${ }^{9}$ Os ataques eram muito similares aos do caso anterior, mas havia também uma perda urinária.

O paciente contou que, com aproximadamente 4 anos, aprendeu com as crianças da rua a se masturbar ("tocar violino"). O pai percebeu logo e proibiu terminantemente. Naquele tempo, ele era muito medroso (ängstlich), tinha muito medo (Angst), principalmente à noite. Tinha também muito medo de cachorros. Quando via um cachorro passeando na rua, ele chorava e gritava:

- Querido cachorro, não me toque, eu quero ser bonzinho.

Entendia por "ser bonzinho", "não tocar mais violino".

O paciente é o mais velho de três irmãos (tem duas irmãs mais novas) e é o predileto da mãe. Segundo relato da mãe, até os 4 anos (início do medo [Angst] e da masturbação), ele se desenvolveu normalmente e era completamente saudável, exceto pela constipação crônica de que sofria. Muitas vezes ele se sujava e era "mais difícil do que para outras crianças deixar de se sujar", segundo a mãe. Agora, demonstra uma preferência pelo pai: ele beija o pai várias vezes ao dia, pela manhã, antes de irem à mesa, depois de saírem da mesa, antes de dormir.

- Na mamãe, eu também dou um beijo de manhã e de noite. Responde ele, quando eu pergunto.

Mas ele prefere dormir com o pai na cama. Já na época em que tinha medo (Angst) à noite, o pai o levava para sua cama e ele se acalmava melhor do que com a mãe. Ele também prefere brincar com meninos do que com meninas. Seu brincar é tranquilo, tendendo à passividade, e ele não gosta das brincadeiras de luta dos meninos. ${ }^{10}$

Max era seu companheiro de brincadeiras. O paciente também viu as "indecências" que Max fazia: "Ele colocava a mão por debaixo da saia das meninas". Com uma enorme resistência, ele confessou que viu Max tentando ter relações com meninas e com a irmãzinha do paciente e que também desejava ter relações com sua própria irmãzinha, mas tinha medo de seu pai.

Vemos claramente nesses relatos um reforço dos componentes homossexuais e um recalque (Verdrängung) enérgico dos componentes heterossexuais.

${ }^{9} \mathrm{Em}$ alemão, Sauberkeit se refere à criança que já deixou as fraldas, ou seja, que já aprendeu o controle esfincteriano. (N. da T.)

${ }^{10}$ Ele gosta de brincar de soldado, mas não é ativo como um "guerreiro": brinca com fósforos e outros objetos de soldados como as meninas brincam de boneca. (N.A.) 
O garoto também indica o ponto exato de virada de seu desenvolvimento, numa idade próxima dos 4 anos, quando eclodem seus primeiros sintomas neuróticos, como pavor noturno e fobias. Até esse momento, a mãe tinha um papel fundamental em sua vida afetiva. Ele era seu predileto, muito mimado e cuidado por ela. Esse amor materno despertou nele um amor igual - a favor disso, falam seus sintomas. Sua fobia de cachorro é o medo deslocado do pai, uma vez que sua curiosa expressão - "Cão, serei bonzinho" [isto é, não me masturbarei] — se refere na realidade ao pai, que lhe proibiu a masturbação. Ao mesmo tempo, manifesta-se com o pavor noturno seu amor pelo pai, cuja proximidade o acalma melhor e mais depressa. Portanto, nessa época, havia em sua alma (Seele) um conflito de sentimentos opostos em relação ao pai. $\mathrm{O}$ deslocamento do medo neurótico para o cachorro tinha o claro propósito de salvar o amor nutrido pelo pai e livrá-lo das moções hostis opostas. ${ }^{11}$ Essa hostilidade em relação ao pai, que o próprio paciente atribuiu à proibição da masturbação, é no entanto consequência da última moção libidinal escondida contra a mãe, da qual derivam o ciúme e a rivalidade. Na luta entre o amor pelo pai e o amor pela mãe, venceu o primeiro (com a ajuda da fobia de cachorro), e sobre o segundo recaiu o recalcamento (Verdrängung). Assim, o recalcamento da libido heterossexual se converteu em medo (Angst) neurótico e em fobia, embora também tenha contribuído para a supressão (Unterdrückung) da hostilidade contra o pai. Por outro lado, o amor suprimido (unterdrückte) pela mãe foi parcialmente substituído pelo aumento do amor pelo pai: o recalcamento (Verdrängung) da heterossexualidade levou ao reforço da homossexualidade.

Mais tarde, por transferência (Übertragung), o fenômeno se repetiria, de maneira tipicamente neurótica. Os sentimentos heterossexuais foram direcionados à irmã (transferência da mãe) e desejos incestuosos foram despertados e imediatamente recalcados (verdrängt), em virtude do antigo medo do pai.

O garoto tem um caráter anal pronunciado (pedantismo, exagero com limpeza etc.). Quando bebê, apresentou inúmeros sintomas típicos de erotismo anal. Este último parece-me em alguma medida relacionado a uma

${ }^{11}$ Tais fobias (de cavalos, cachorros, gatos ou galinhas e outras histerias) são, creio eu, manifestações tão comuns na infância quanto o pavor noturno. Na análise, elas se expressam na maior parte das vezes como um deslocamento do medo de um dos pais para um animal. Não saberia dizer se a fobia tão comum de camundongos e ratos (Mäuse und Ratten) obedece ao mesmo mecanismo. (N.A.) 


\section{CLÁSSICO DA PSICANÁLISE}

pronunciada homossexualidade que pode ser vista como uma tendência constitucional impedindo o desenvolvimento dos genitais para que não sejam a principal zona erógena, aumentando a dúvida no próprio sexo e favorecendo a fixação na homossexualidade. Nesse caso, a repressão enérgica e precoce da masturbação talvez tenha tido também um papel favorecedor importante.

Nesse caso, assim como no anterior, eu não pude executar um tratamento psicanalítico, como deveria ser feito para fins terapêuticos. Só tomei providências para evitar excitações específicas, reduzir a pulsão sexual demasiadamente alta e consegui êxitos terapêuticos bastante favoráveis. Em três ou quatro semanas, o estado do garoto melhorou tanto que, em vez de trinta a cinquenta ataques por dia, havia apenas dois ou três. Mas, certo dia, ele foi surrado na escola, por um professor, com uma vara e com tal força que, no quarto dia, eu ainda via manchas escuras em suas nádegas. Logo após, os ataques voltaram a ser muito frequentes. Depois de ficar alguns dias em casa, o paciente se acalmou e passou uns dois dias sem ataques. Quando voltou à escola, voltaram novamente os ataques, mas não com tanta frequência como antes da surra; vômitos e dores de cabeça se somaram posteriormente. A usual transferência do pai recaiu sobre o professor e, pela surra, despertou os antigos complexos do medo e da animosidade, cuja consequência foi o reforço dos sintomas neuróticos. Vale destacar que o paciente sempre gostou muito desse professor. me disse.

- Quando penso na escola, tenho que pensar logo no professor P. - ele

Esse professor era muito severo: em toda aula, ele surrava algum aluno. Dois alunos seguravam a cabeça e as pernas daquele que seria surrado. $O$ professor esticava a calça do garoto e batia e ria, demonstrando ter prazer com a situação. A relação sadomasoquista entre professor e aluno é, nesse caso, bem evidente. É inútil fazer qualquer comentário sobre o significado desses fatos para a pedagogia.

Pelo relato do caso, a relação dos ataques com a masturbação é bastante clara. Em ambas as crianças, a pulsão sexual genital despertou cedo demais e teve uma intensidade anormal. Uma intensificação anormal da masturbação é a consequência da intensidade dessa pulsão. Em dado momento, a masturbação de ambas as crianças foi combatida energicamente e recalcada (verdrängt), e depois surgiram os ataques. Eles são, até certo ponto, uma substituição da masturbação. Tudo o que provoca a pulsão sexual (Sexualtrieb) favorece seu aparecimento. Evitar essas provocações (Reize) de natureza sexual reduz os ataques em número e intensidade. Pode-se facilmente conceber um ataque 
como um orgasmo que surge repentinamente. No auge de um orgasmo, como se sabe, há muitas vezes uma alteração de consciência. As expressões faciais que acompanham os ataques - como olhos arregalados, olhos virados para cima, musculatura facial tensionada com leves espasmos - são igualmente perceptíveis no êxtase orgástico. ${ }^{12}$

Citação/Citation: Wulff, M. (2016, setembro). Contribuições para a sexualidade infantil, Revista Latinoamericana de Psicopatologia Fundamental, 19(3), 512-526.

Editores do artigo/Editors: Prof. Dr. Manoel T. Berlinck

\section{Moshé WulfF (1878-1971)}

Psicanalista russo, pioneiro na psicanálise com crianças e na clínica com distúrbios alimentares; Tradutor de várias obras de Freud para o russo e o hebraico; Médico da família do Homem de Lobos; Cofundador da Associação Psicanalítica de Pesquisas sobre a criação artística, primeira associação freudiana russa e da primeira Sociedade psicanalítica Estado de Israel junto com Max Eitingon.

${ }^{12}$ Eu já havia dado meu trabalho como pronto quando me caiu nas mãos um trabalho sobre um caso de Sadger publicado no último anuário de Pesquisas Psicanalíticas e Psicopatológicas, II volume, $1 \mathrm{H}$, intitulado "Ein Fall von multipler Perversion mit hysterischen Absenzen" ("Um caso de perversão múltipla com ausências histéricas"). É notável a semelhança da neurose de um adulto, já bem avançada, com o início de seu desenvolvimento numa criança.

This is an open-access article, which permits unrestricted use, distri-

\section{(cc) BY-NC} bution, and reproduction in any medium for non-commercial purposes provided the original authors and sources are credited. 